\title{
LATE QUATERNARY STRATIGRAPHY AND SEDIMENTOLOGY OF THE CENTRAL NORTH ATLANTIC: A PROGRESS REPORT
}

\author{
S.R. TROELSTRA ${ }^{1)}$, G.M. GANSSEN ${ }^{1)}$, E.J. SENNEMA ${ }^{1)}$, G.Th. KLAVER ${ }^{1)}$, C. ANDERLIESTEN ${ }^{2)}$, \\ K. VAN DEN BORG ${ }^{2)}$ and A.M.F. DE JONG ${ }^{2)}$ \\ 1) Geomarine Center, Institute of Earth Sciences, Free University, P.O. Box 7161, 1007 MC Amsterdam, The Netherlands \\ 2) Robert J. van der Graaff Laboratorium, State University Utrecht, Box 80.000, 3508 TA Utrecht, The Netherlands
}

\begin{abstract}
The marine geological research program of the Department of Sedimentary Geology at the Free University of Amsterdam focuses on three areas: Banda Sea, central North Atlantic and the Mediterranean. Late Quaternary deep-sea cores taken in these areas are analysed in order to reconstruct changes in paleoceanography as reflected in the sedimentary record. Radiocarbon datings through the cores provide the necessary stratigraphic framework. The Utrecht tandem Accelerator Mass Spectrometer (AMS) allows radiocarbon dating on minutes samples (10-25 mg carbonate) and is therefore an excellent tool for core studies. This paper concentrates on results obtained from the central North Atlantic material.

The Atlantic $\mathrm{CaCO}_{3}$ profile shows a maximum at the last climate optimum at $6 \mathrm{ka}$ and a minimum at the last glacial maximum at $18 \mathrm{ka} \mathrm{[1].} \mathrm{This} \mathrm{is} \mathrm{also} \mathrm{observed} \mathrm{in} \mathrm{our} \mathrm{material,} \mathrm{and} \mathrm{confirmed} \mathrm{by} \mathrm{radiocarbon} \mathrm{dating.} \mathrm{It} \mathrm{is} \mathrm{shown} \mathrm{that} \mathrm{sedimentation} \mathrm{rates} \mathrm{are}$ distinctly higher during the period of deglaciation. The dating also provides a framework for the timing of the retreat of the polar front.

A surface layer of pteropod shells covers parts of the Atlantic Ocean floor at about $3000 \mathrm{~m}$ depth. Many shells show Fe/Mn staining. The AMS technique allows dating of single shells, and proves that the stained specimens are considerably older than the unstained shells. Implications for this phenomenon and for the contribution of aragonite to the sediment are given.
\end{abstract}

\section{Introduction}

The material described in this paper was collected during the August/September 1986 cruise of the R/V Tyro in the central North Atlantic. The cruise is part of the Amsterdam APNAP (Actuomicropaleontology Paleoceanography North Atlantic Project) encompassing plankton-net and sediment-trap sampling, box- and piston-coring in order to reconstruct the late Quaternary paleoceanographic history of this area. Material was collected along a traverse running east of and parallel to the Mid-Atlantic Ridge from $53^{\circ} \mathrm{N} 27^{\circ} \mathrm{W}$ to $26^{\circ} \mathrm{N}$ $42^{\circ} \mathrm{W}$ (fig. 1).

Besides micropaleontological studies, shore-based analyses on the core- and net-samples include grain-size and element distribution, $\mathrm{CaCO}_{3}$ content, stable isotopes and radiocarbon datings. All research is still in progress, so results must be considered preliminary.

This paper focuses on two aspects of the paleoceanography of the area: (1) the position of the polar front during the last glacial and the timing of its retreat coupled with consequences for sedimentation, and (2) the presence of pteropod shells, many of them $\mathrm{Fe} / \mathrm{Mn}$ stained, on the surface layer of various box-cores, in particular a $2 \mathrm{~cm}$ thick layer on T86-5B $(\mathrm{B}=$ box-core $)$. The latter aspect is a good example of the potential of the AMS technique, as datings could be performed on single pteropod shells with an average weight of 17.8 mg.

\section{Material and experimental methods}

From the 14 box-cores taken during the APNAP-86 cruise, 5 were selected for the topics presented here. The submarine unconsolidated muds were sieved to separate the grain-fraction that mainly consists of foraminiferal calcite $(>63 \mu \mathrm{m})$. After treatment of this fraction with orthophosphoric acid the evolved $\mathrm{CO}_{2}$ is reduced to graphite using finely divided iron powder in the presence of excess hydrogen at $920 \mathrm{~K}$ [2]. After pressing the mixture of iron and graphite into a hole of an aluminium holder, it is loaded into one of the 16 positions of the sample wheel. The ${ }^{14} \mathrm{C}$ measurements have been performed using the Utrecht tandem accelerator [3].

\section{The position of the polar front during the last glacial}

One of the targets of APNAP is to characterize water masses in terms of their microfaunal and floral content (foraminifera, pteropods, calcareous nannoplankton). Systematic sampling of the water column by planktonnets has been carried out from $53^{\circ}$ to $26^{\circ} \mathrm{N}$. Then this 


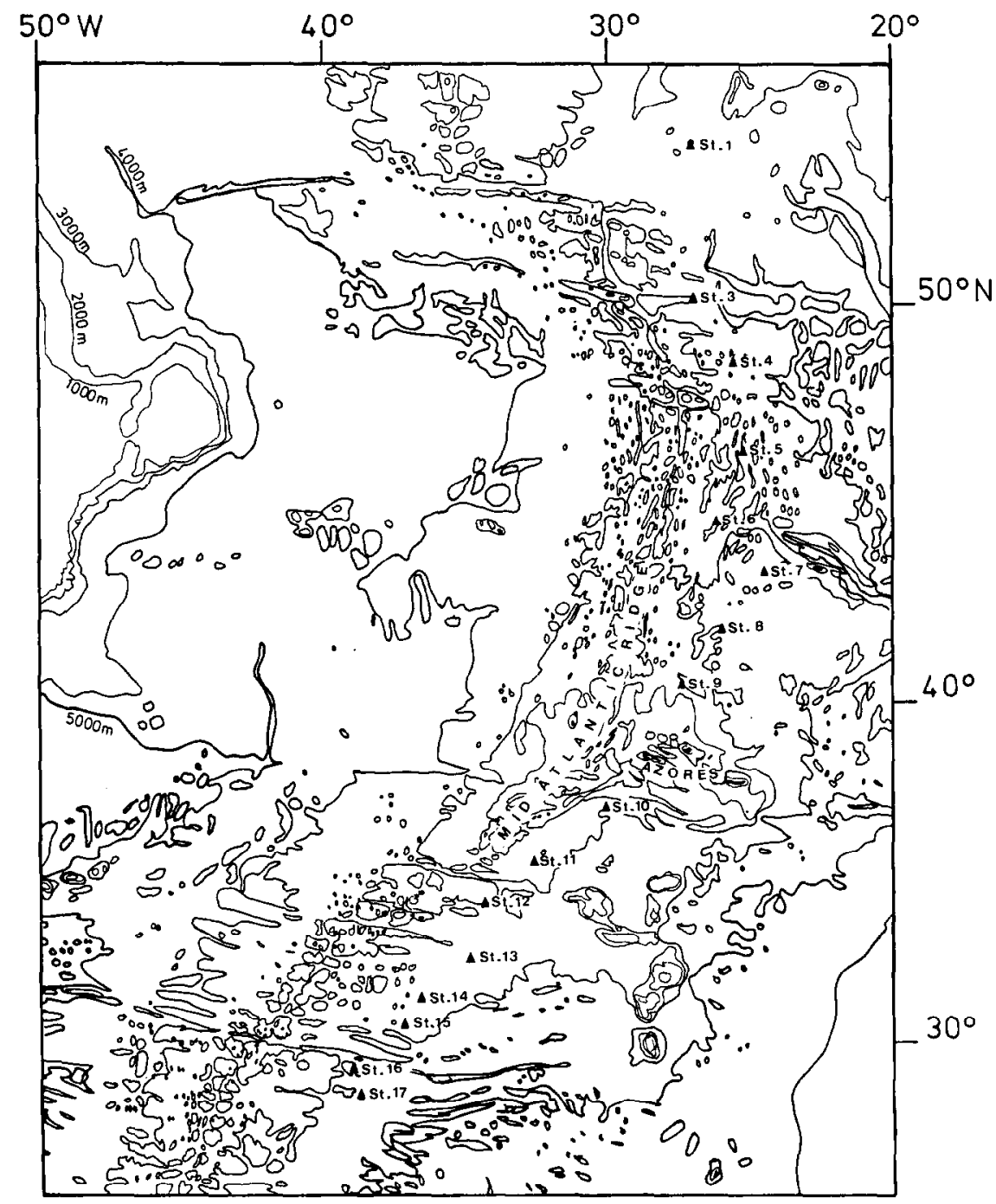

Fig. 1. Bathymetric map of the central North Atlantic, APNAP stations (box- and piston-cores, net samples) are indicated by triangles.

developed tool is used to analyse the micofaunal/floral content of box and piston cores through time and to record compositional changes in order to reconstruct the paleoceanographic history of the North Atlantic during the upper Pleistocene. Each station recorded on fig. 1 generally consist of plankton-net samples and a box- and/or piston-core. Fig. 2 shows results from 4 box cores which we have chosen for more detailed analysis. Eight samples were taken for AMS ${ }^{14} \mathrm{C}$ dating. Calcium carbonate measurements were performed continuously through the cores with sample intervals between 1 and $3 \mathrm{~cm}$.

As can be seen from fig. 2 all cores show the same $\mathrm{CaCO}_{3}$ pattern, with high values near the top and decreasing values downcore. For the cores with maxi- mum recovery (10S and $15 \mathrm{~S}, \mathrm{~S}=$ Scripps large volume box-core) an increase in $\mathrm{CaCO}_{3}$ content towards the bottom can be seen. In absolute values, however, a distinct change occurs between core $8 \mathrm{~B}$ and 7B. The drop in $\mathrm{CaCO}_{3}$ content for cores $8 \mathrm{~B}$ to $15 \mathrm{~S}$ is in the order of $15 \%$, but for core $7 \mathrm{~B}$ in the order of $40 \%$. Inspection of the washed sample residues through the core reveals that in core $7 \mathrm{~B}$ decreased values correspond with increasing amounts of clastic (rafted) material. The carbonate pattern is thus largely governed by dilution with minor dissolution. Core $8 \mathrm{~B}$ contains only minimal amounts of rafted material; core $10 \mathrm{~S}$ and $15 \mathrm{~S}$ are free of clastics. The drop in $\mathrm{CaCO}_{3}$ content in cores $8 \mathrm{~B}$ to $15 \mathrm{~S}$ must thus be explained by factors other than dilution, possibly dissolution and/or changes in primary produc- 

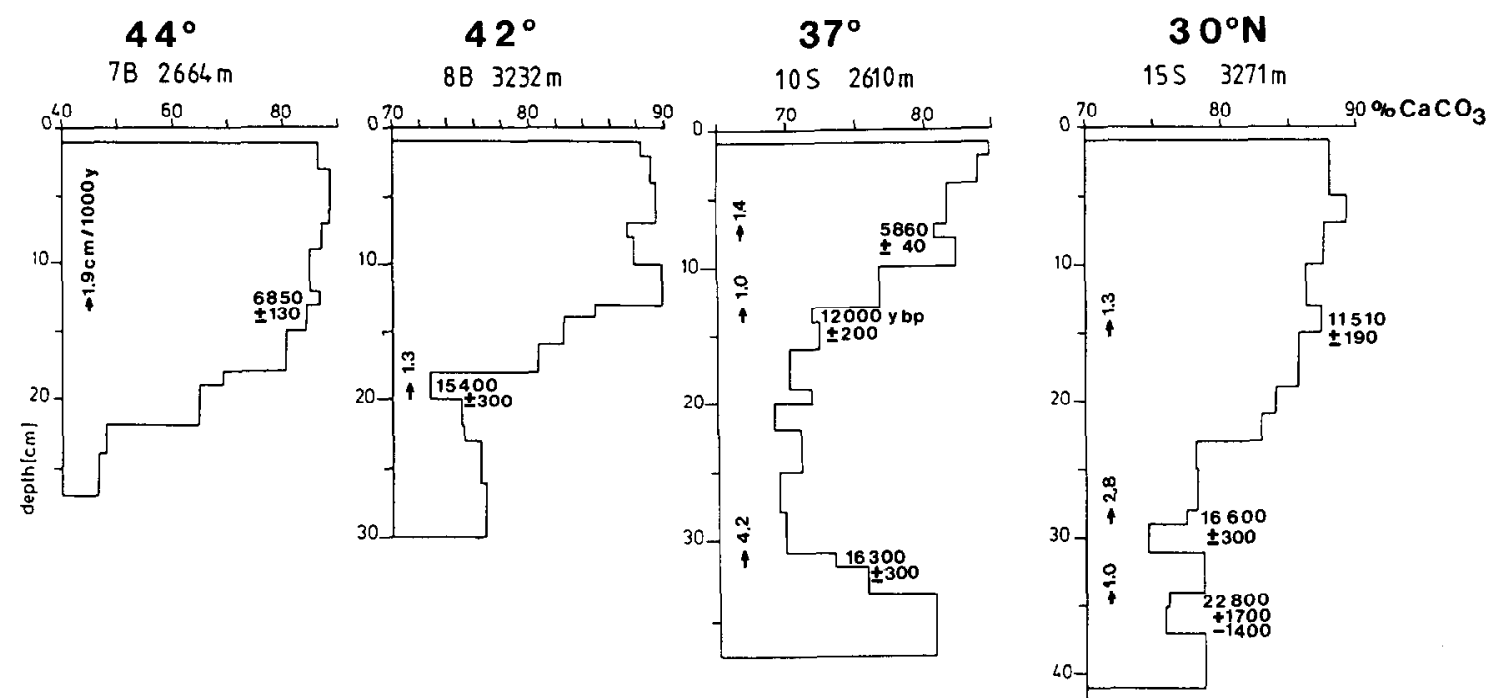

Fig. 2. $\mathrm{CaCO}_{3}$ stratigraphy and radiocarbon ages of 4 box-cores discussed in this paper. Note higher sedimentation rates during deglaciation.

tion. Fragmentation of foraminiferal tests in these cores in conspicuous, although not severe. Sedimentation rates through the cores are not constant, as can be seen from fig. 2. During the Holocene rates fluctuate between 1.3 and $1.9 \mathrm{~cm} / \mathrm{ka}$. Higher rates $(2.8-4.2 \mathrm{~cm} / \mathrm{ka})$ are recorded during the deglaciation phase. The presence of common rafted material in T86-7B (and also in the northern cores T86-1B to $6 \mathrm{~B}$ ) is cvidence for the presence of polar ice at the time of sediment accumulation. The decreasing amounts of rafted material upcore and its eventual absence in the uppermost part of the core is indicative of the melting ice and subsequent northward retreat of the polar front. Future AMS work will give us an exact constraint on this process.

\section{Pteropod preservation in the deep-sea}

The distribution patterns of foraminifera and pteropods on the sea-floor differ considerably. Pteropods dissolve more rapidly because their shells are made of aragonite. Below the thermocline most seawater is undersaturated in aragonite, so inclusion of pteropod tests in the sediment is an exception [4]. Maximum depth for a pteropod ooze in the Atlantic is approximately $2800 \mathrm{~m}$, with only a few deeper records [4]. Ganssen and Lutze [5] located the position of the aragonite compensation depth (ACD) along the northeastern continental margin at $45^{\circ} \mathrm{N}$ at approximately $1000 \mathrm{~m}$, caused by high productivity. Table 1 lists the presence/absence of pteropod shells on the surface sediment layer from the box-cores under discussion. Although absent from the core taken at $3232 \mathrm{~m}$, pteropods can still be observed in core T86-15S from the depth of $3271 \mathrm{~m}$. Obviously, the position of the ACD in this area can well be below $3000 \mathrm{~m}$.

Of particular interest is the occurrence of a $2 \mathrm{~cm}$ thick pteropod layer on the surface of core T86-5B, taken at a depth of $3021 \mathrm{~m}$. The sediment can be described as a pteropod ooze and is almost monospccific in composition. The majority of the shells can be assigned to Diacria trispinosa forma atlantica with minor D. trispinosa forma trispinosa and Clio pyramidata s.l. This assemblage is in accordance with distribution patterns for the modern northern Atlantic [6]. The Diacria formae can be distinguished on shape and color; forma atlantica is firmly built with a reddishbrown test, while forma trispinosa is slender, with only a dark-colored rim [6]. Fe/Mn coating in varying degrees can be seen on many of the shells.

Similar pteropod layers have been described from

Table 1

Location, water depth and recovery of box-cores described in this paper. The presence/absence of pteropods is indicated.

\begin{tabular}{lllll}
\hline Box-core & Latitude & Longitude & $\begin{array}{l}\text { Water } \\
\text { depth } \\
\text { (m) }\end{array}$ & $\begin{array}{l}\text { Recovery } \\
\text { (cm) }\end{array}$ \\
\hline T86-15S & $30^{\circ} 29^{\prime} 30^{\prime \prime}$ & $36^{\circ} 57^{\prime} 30^{\prime \prime}$ & 3271 & $41^{\text {a) }}$ \\
T86-10S & $37^{\circ} 05^{\prime} 16^{\prime \prime}$ & $30^{\circ} 02^{\prime} 50^{\prime \prime}$ & 2610 & $36^{\text {b) }}$ \\
T86-8B & $42^{\circ} 15^{\prime} 30^{\prime \prime}$ & $25^{\circ} 40^{\prime} 50^{\prime \prime}$ & 3232 & $30^{\text {d) }}$ \\
T86-7B & $43^{\circ} 55^{\prime} 10^{\prime \prime}$ & $24^{\circ} 58^{\prime} 10^{\prime \prime}$ & 2664 & $28^{\text {b) }}$ \\
T86-5B & $46^{\circ} 53^{\prime} 02^{\prime \prime}$ & $25^{\circ} 21^{\prime} 09^{\prime \prime}$ & 3021 & $38^{\text {c) }}$ \\
\hline
\end{tabular}

\footnotetext{
a) Pteropods present.

b) Pteropods common.

c) Pteropods abundant.

d) Pteropods absent.
} 
the Rio Grande Rise (S-Atlantic) [7,8]. In a detailed study [8] the authors carried out ${ }^{14} \mathrm{C}$ analyses on both stained and unstained specimens (bulk samples) and found that the stained shells were much older $(8045 \pm$ 180 versus $3240 \pm 125$ yr BP). Discrepancies existed between the age of the pteropod shells and that of the underlying sediment. Price et al. [8] concluded that the presence of such a pteropod ooze should be explained in terms of lag of burial associated with recent increases in preservation and winnowing.

To test this hypothesis we decided to carry out detailed studies on our material. The availability of the AMS enabled us to date single specimens of Diacria. Other analyses such a grain-size and element distribution, stable isotopes and micropaleontological studies are still in progress, and could not be included in this paper.

A sample from box-core T86-5B taken at $33 \mathrm{~cm}$ from unit $\mathrm{D}$ (for description of the core see table 1 and fig. 3) revealed an age of $14600 \pm 200 \mathrm{yr} B P$ indicating an average sedimentation rate of $2.3 \mathrm{~cm} / \mathrm{ka}$, provided that the top of the core represents modern sediments. Although we have no dating of the top sediment yet, the age of the youngest pteropod shell $(510 \pm 90 \mathrm{yr}$ BP)

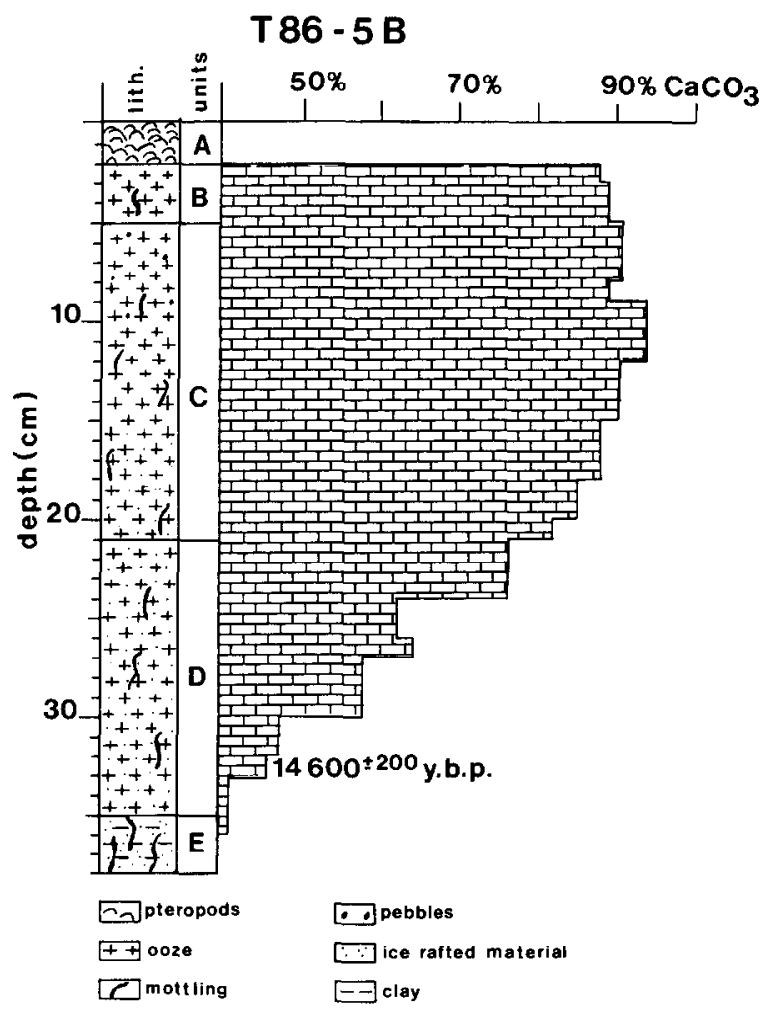

Fig. 3. Generalized lithology, lithological units and carbonate stratigraphy of box-core T86-5B. The pteropods discussed in this paper derive from unit $A$. might be a proof of continuous sedimentation. Interpreting the data, we can conclude that box-core T86-5B represents the sedimentological history of the last 16000 $\mathrm{yr}$ at this location. The upcore decrease of rafted material is indicative of the retreat of the polar front. Low $\mathrm{CaCO}_{3}$ values through this interval are mainly caused by dilution and less so by dissolution, which can also be substantiated by the presence of relatively well-preserved foraminifera.

Aragonite preservation is limited to units B (only few fragments) and especially $A$ (the pteropod layer). This is in agreement with Berner [4] who states that pteropods undergo most dissolution while lying on the bottom.

\section{Pteropod dating results and discussion}

As we have described above, two sets of pteropod shells ranging from unstained to dark stained specimens were collected from the surface layer of box T86-5B. Radiocarbon dating results are shown in fig. 4 and table 2. Specimens range in age from $510 \pm 90$ to $3170 \pm 120$ yr BP, the latter age being an exception, and most specimens yielding an age of approximately $2000 \mathrm{yr}$ BP and younger. $A$ first conclusion might thus be that aragonite preservation at this location takes place during the last $2-3000 \mathrm{yr}$ suggesting a quite recent change in oceanography. Fig. 4 also shows a good correlation between age and $\mathrm{Fe} / \mathrm{Mn}$ staining, e.g. staining progresses with increasing age and is a continuous process.

Pending the results of other analyses, such as grain size and an accurate dating of the top sediment, we are still faced with several questions:

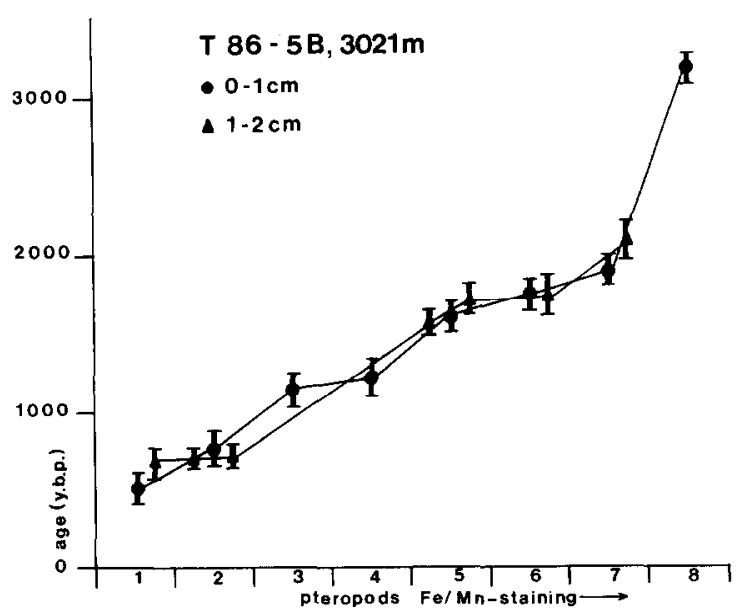

Fig. 4. Diagram showing the correlation between radiocarbon age and $\mathrm{Fe} / \mathrm{Mn}$ staining. The two data sets are marked with $\bullet$ (complete gradation unstained " 1 " to dark stained " 8 " specimen) and $\triangle$ (specimens used for checking). 
Table 2

AMS-determined ${ }^{14} \mathrm{C}$ ages in $\mathrm{yr}$ BP for two series of pteropod-shells from box-core T86-5B. The species measured is Diacria trispinosa s.l. Specimens are labelled in order of increasing $\mathrm{Fe} / \mathrm{Mn}$ staining. Age deduced from measured ${ }^{14} \mathrm{C} /{ }^{12} \mathrm{C}$ ratio. Correction applied for isotope fractionation by normalisation with known $\delta^{13} \mathrm{C}$ to $\delta^{13} \mathrm{C}=-25 \%$. No correction applied for reservoir age.

\begin{tabular}{lrr}
\hline & $\begin{array}{l}\text { Sample 1 } \\
(0-1 \mathrm{~cm})\end{array}$ & \multicolumn{1}{c}{$\begin{array}{l}\text { Sample 2 } \\
(1-2 \mathrm{~cm})\end{array}$} \\
\hline Sp. 1 & $510 \pm 90$ & $680 \pm 110$ \\
Sp. 2 & $770 \pm 110$ & $710 \pm 80$ \\
Sp. 3 & $1140 \pm 90$ & $720 \pm 110$ \\
Sp. 4 & $1210 \pm 110$ & $1600 \pm 90$ \\
Sp. 5 & $1590 \pm 80$ & $1710 \pm 110$ \\
Sp. 6 & $1740 \pm 110$ & $1740 \pm 130$ \\
Sp. 7 & $1870 \pm 90$ & $2100 \pm 130$ \\
Sp. 8 & $3170 \pm 120$ & \\
\hline
\end{tabular}

(1) Why is the assemblage almost monospecific, and why are all Diacria specimens of almost the same large size? As to the first part of the question, we can say that modern pteropod assemblages at this latitude are little diverse, and consist mainly of Diacria trispinosa s.l. and Clio pryramidata s.1 [7]. Indeed, minor quantitaties of Clio pyramidata s.l. are present in our material, but they are extremely fragile, and desintegrate on touch. We may thus be dealing with selective dissolution, Clio being the more dissolution susceptible form. As to the apparent size sorting matters are more complex. A possible solution might be, that the pteropod layer is not a result of autochthonous sedimentation, but due to size-sorting by mass-flow. Alternatively, the size-sorting may be the result of winnowing, the smaller specimens washed out.
(2) Are we dealing with a very localized phenomenon or are such pteropod layers more wide-spread in this area? Table 1 shows that pteropod preservation at depths exceeding $3000 \mathrm{~m}$ occurs, and we will repeat our ${ }^{14} \mathrm{C}$ datings on other cores in the near future. Also we will focus on pteropod deposits during our 1988 and 1989 cruises in this area.

The results of our APNAP cruise must thus be considered preliminary; more detailed studies will follow.

These investigations in the program of the Foundation for Fundamental Research on Matter (FOM) have been supported in part by the Netherlands Technological Foundation (STW) and by the Netherlands Organisation for Advancement of Pure Research (ZWO).

The APNAP-1986 expedition was financed by the N.R.Z. (Netherlands Council for Oceanic Research). The help of captain and crew of the R.V. Tyro and technicians from the NIOZ and RGD is gratefully acknowledged.

\section{References}

[1] J.T. Crowley, Geophys, Monograph 32 (1985) 271.

[2] G. Hut, H.G. Oslund and K. van der Borg, Radiocarbon. 28 (1986) 186.

[3] K. van der Borg, C. Alderliesten, C.M. Houston, A.F.M. de Jong and N.A. van Zwol, these Proceedings (AMS '87) Nucl. Instr. and Meth. B29 (1987) 143.

[4] R.A. Berner, Mar. Sci. 6 (1977) 243.

[5] G.M. Ganssen and G.F. Lutze, Meteor Forsch. Ergebnisse, C36 (1982) 57.

[6] T. Pafort-van Iersel, Beaufortia 32 (6) (1982) 97.

[7] M. Melguen and J. Thiede, Mar. Geol. 17 (1974) 341.

[8] B.A. Price, J.S. Killingley and W.H. Berger, Mar. Geol. 64 (1985) 217. 